\title{
Artroplastia interfalángica proximal de dedo de la mano con doble injerto osteocondral de costilla. Reporte de un caso y descripción de la técnica quirúrgica
}

Ricardo M. Gardenal, Renzo A. Carcuro, Jorge A. Bichara, Matías S. Seri, Sebastián J. Faccendini, Iván Camizasca, Eddy Massolas, Nicolás Scaiano, Martín E. Romaldini, Juan Ignacio Godoy

Sanatorio Plaza, Rosario, Argentina

\begin{abstract}
RESUMEN
Se presenta el caso de un hombre de 27 años con una lesión grave articular interfalángica proximal en el dedo anular de la mano derecha, provocada por un proyectil de arma de fuego, que fue tratada con doble injerto osteocondral de costilla. Tenía una fractura expuesta y déficit de stock óseo y cartilaginoso tanto en la primera como en la segunda falange. Luego de la limpieza inicial, a las 3 semanas, se realizó una artroplastia interfalángica proximal con doble injerto osteocondral de costilla y fijador externo distractor de Suzuki. Se describe con detalle la técnica quirúrgica. A las 10 semanas posoperatorias, la flexión activa interfalángica era de $75^{\circ}$ y la extensión activa, de $-15^{\circ}$, con articulación estable. Alta laboral a los 3 meses de la cirugía, sin dolor y un puntaje DASH de 14,2. Las radiografías mostraron la incorporación de los injertos, sin reabsorción y con una articulación congruente. Se valora la ventaja de esta técnica en cuanto a la escasa morbilidad para la zona dadora y la versatilidad para las reconstrucciones con defectos articulares. El resultado funcional temprano subjetivo y objetivo fue satisfactorio. No se pueden descartar complicaciones futuras.
\end{abstract}

Palabras clave: Artroplastia interfalángica proximal; injerto osteocondral; costilla.

Nivel de Evidencia: IV

Proximal Interphalangeal Finger Arthroplasty with Double Osteochondral Rib Graft. Case Report and Description of the Surgical Technique

\begin{abstract}
We present the case of a 27-year-old male patient with a gunshot wound and severe proximal interphalangeal joint injury in the ring finger of the right hand, treated with a double osteochondral rib graft. He had an exposed fracture and a lack of bone and cartilage stock in both the first and second phalanx. After the initial toilette, at 3 weeks, a proximal interphalangeal arthroplasty was performed with a double osteochondral rib graft protected by a Suzuki external distractor. The surgical technique is described in detail. At 10 weeks after surgery, an active interphalangeal joint flexion of $75^{\circ}$ and active extension of $-15^{\circ}$ were verified, without articular instability. The patient returned to work at 3 months after surgery, with no residual pain (0 VAS score) and a DASH score of 14.2 . Radiographs showed incorporated grafts without resorption and a congruent joint. This technique is valued for its low morbidity on the donor site and versatility for joint defect reconstructions. The limitations of our study are mentioned. The clinical case presented obtained a satisfactory subjective and objective early functional outcome. Further complications cannot be ruled out.
\end{abstract}

Keywords: Proximal interphalangeal arthroplasty; osteochondral rib graft.

Level of Evidence: IV

Recibido el 27-10-2020. Aceptado luego de la evaluación el 25-3-2021 • Dr. RICARDO M. GARDENAL・drmartingardenal@ gmail.com

https://orcid.org/0000-0003-0013-9275

Cómo citar este artículo: Gardenal RM, Carcuro RA, Bichara JA, Seri MS, Faccendini SJ, Camizasca I, et al. Artroplastia interfalángica proximal de dedo de la mano con doble injerto osteocondral de costilla. Reporte de un caso y descripción de la técnica quirúrgica. Rev Asoc Argent Ortop Traumatol 2021;86(5):651-658. https://doi.org/10.15417/issn. 1852-7434.2021.86.5.1279 


\section{INTRODUCCIÓN}

Las lesiones traumáticas con compromiso del cartílago articular interfalángico proximal causan severas limitaciones en el rango de movilidad y la destreza digital, lo que perjudica la función global de la mano. ${ }^{1}$

El objetivo de este artículo es exponer el caso de un paciente adulto joven con una lesión articular interfalángica proximal del dedo anular de la mano derecha, provocada por un proyectil de arma de fuego que le causó un déficit de stock óseo y de cartílago articular en la región distal de la primera falange y proximal de la segunda falange. Luego de la limpieza inicial y, en un segundo tiempo quirúrgico, se realizó la artroplastia mediante doble injerto osteocondral de costilla.

\section{CASO CLÍNICO}

Hombre de 27 años que sufrió una fractura expuesta por proyectil de arma de fuego con orificio de entrada y salida, en la articulación interfalángica proximal del dedo anular de la mano derecha. En las radiografías, se observó un compromiso del $40 \%$ de la superficie articular en su sector cubital (con defecto en la región distal de la primera falange y proximal de la segunda falange); además, la fractura se extendía a la diáfisis de la segunda falange (Figura 1).

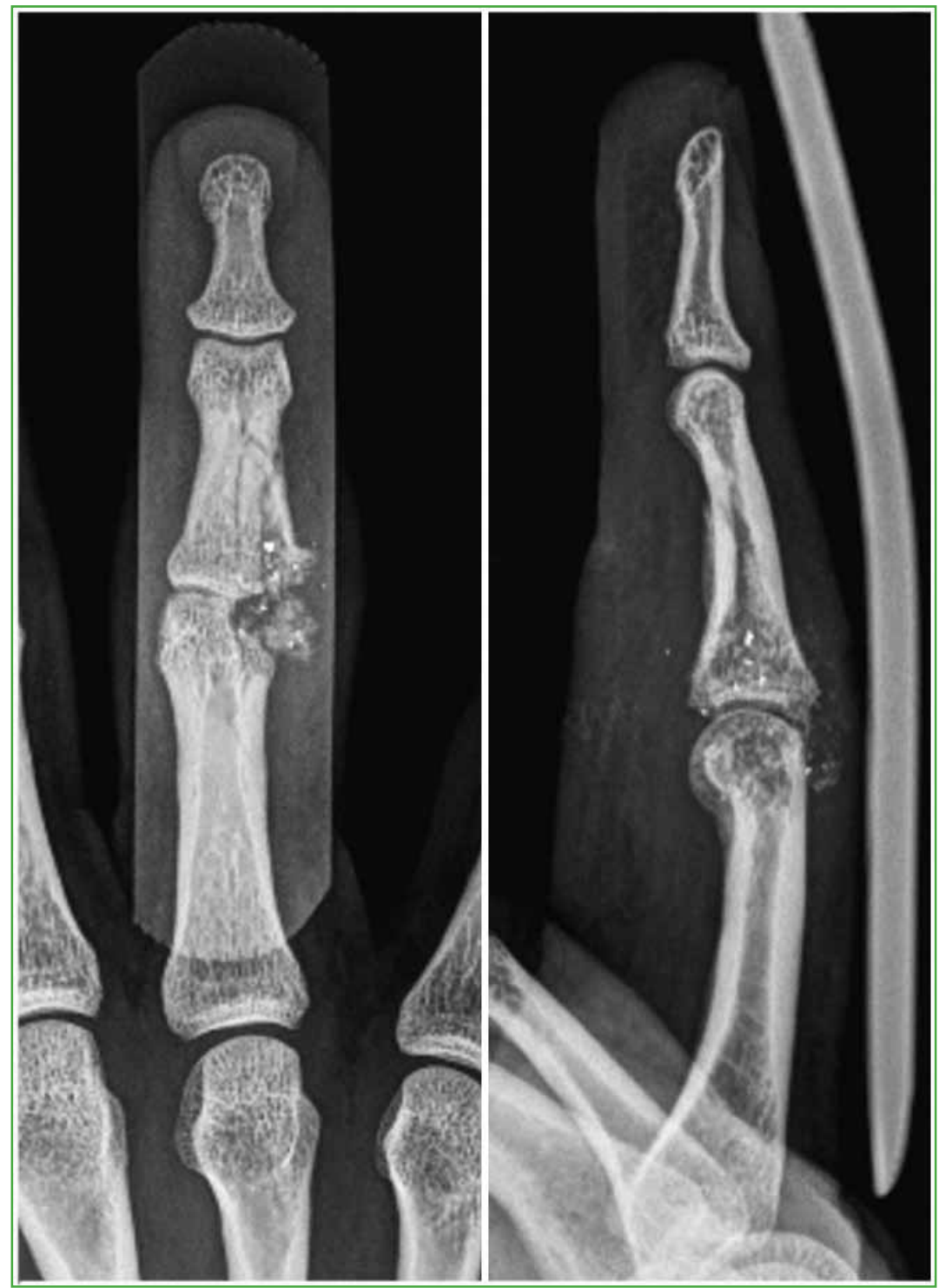

Figura 1. Radiografías de frente y de perfil del dedo anular al ingresar. 
Cuando el paciente ingresó, se realizó una limpieza mecánico-quirúrgica, se le colocó una férula antebraquidigital y recibió profilaxis antibiótica con cefalexina.

En un segundo tiempo, a las tres semanas de la lesión inicial, fue sometido a una artroplastia interfalángica proximal con doble injerto osteocondral de costilla para las falanges proximal y media, protegido con un fijador externo distractor de Suzuki.

\section{Técnica quirúrgica}

\section{Preparación}

Antes de la anestesia, es útil marcar en la piel la unión osteocondral de la octava costilla homolateral al miembro afectado. Esta unión se localiza en la horizontal a nivel de la apófisis espinosa de la vértebra dorsal 12, a dos tercios de la circunferencia del hemitórax, tal como lo describieron Lepage y cols. (Figura 2). ${ }^{2}$

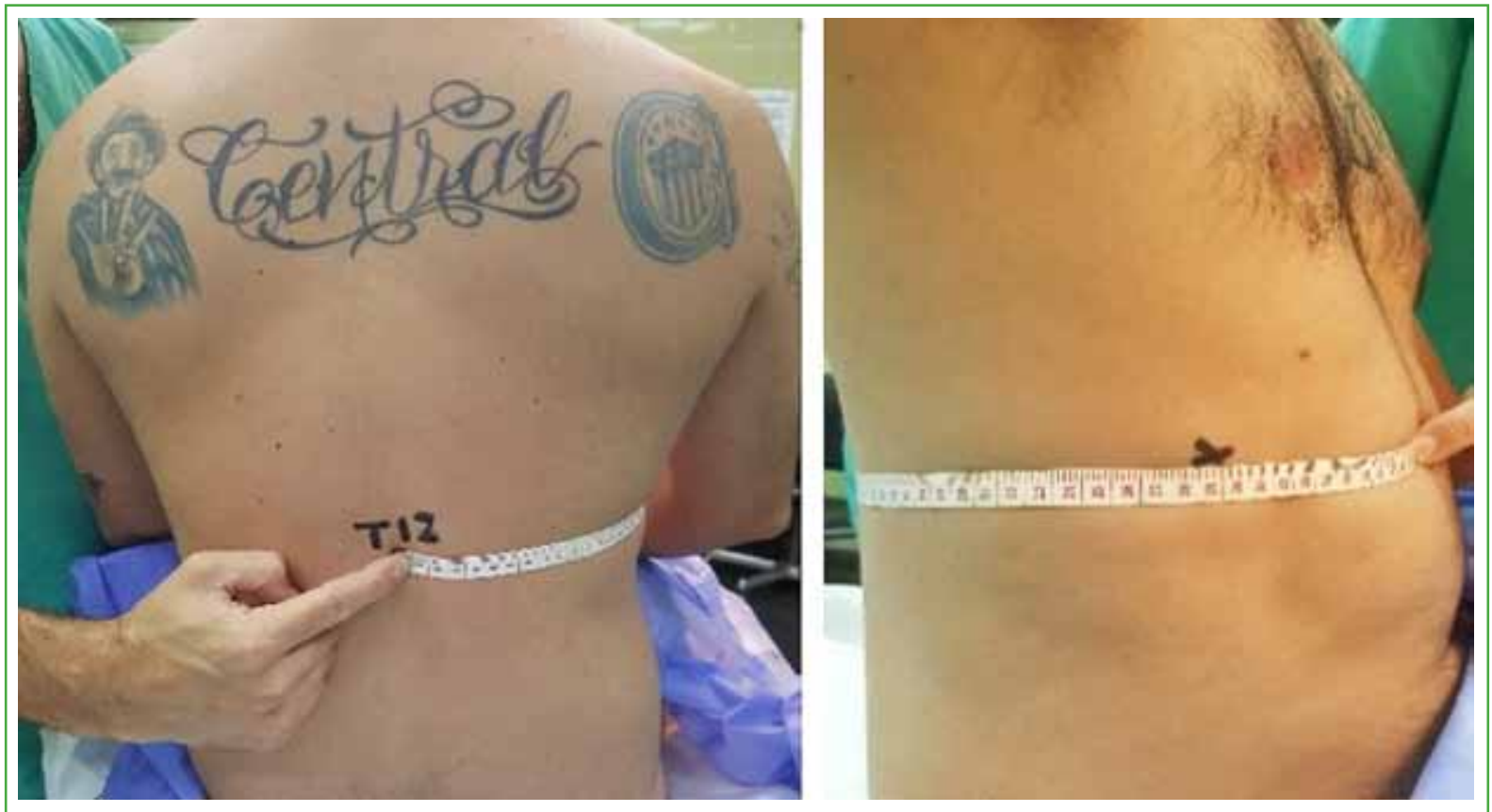

Figura 2. Marcación preoperatoria del sitio dador osteocondral.

\section{Exploración de la lesión}

Se expone la articulación interfalángica proximal del dedo anular mediante una incisión dorsocubital con colgajo en $\mathrm{V}$ de base cubital. Se reseca el cartílago dañado junto con el hueso subcondral y metafisario, y se prepara el defecto para recibir el injerto, tanto en la región distal de la falange proximal como en la base de la falange media. Como la porción ósea del injerto debe ser lo suficientemente grande para permitir una buena fijación, el lecho del injerto se agranda según necesidad, como lo recomiendan Sato y cols. (Figura 3). ${ }^{3}$

\section{Injerto costal}

Utilizamos, según la técnica de Loisel y cols., ${ }^{4}$ una incisión torácica de $4 \mathrm{~cm}$ a lo largo de la cara anterior de la octava costilla, levemente dirigida hacia adentro y abajo. Se seccionan y legran el periostio y el pericondrio de la costilla, separándolos del hueso y el cartílago, respectivamente. Se levanta el injerto, la parte ósea con sierra oscilante y la porción cartilaginosa se corta con bisturí. En nuestro caso, se tomó un injerto tricortical dejando intacta, en el sitio dador, la cara ósea profunda posterior de la costilla y su cartílago (Figura 4). 


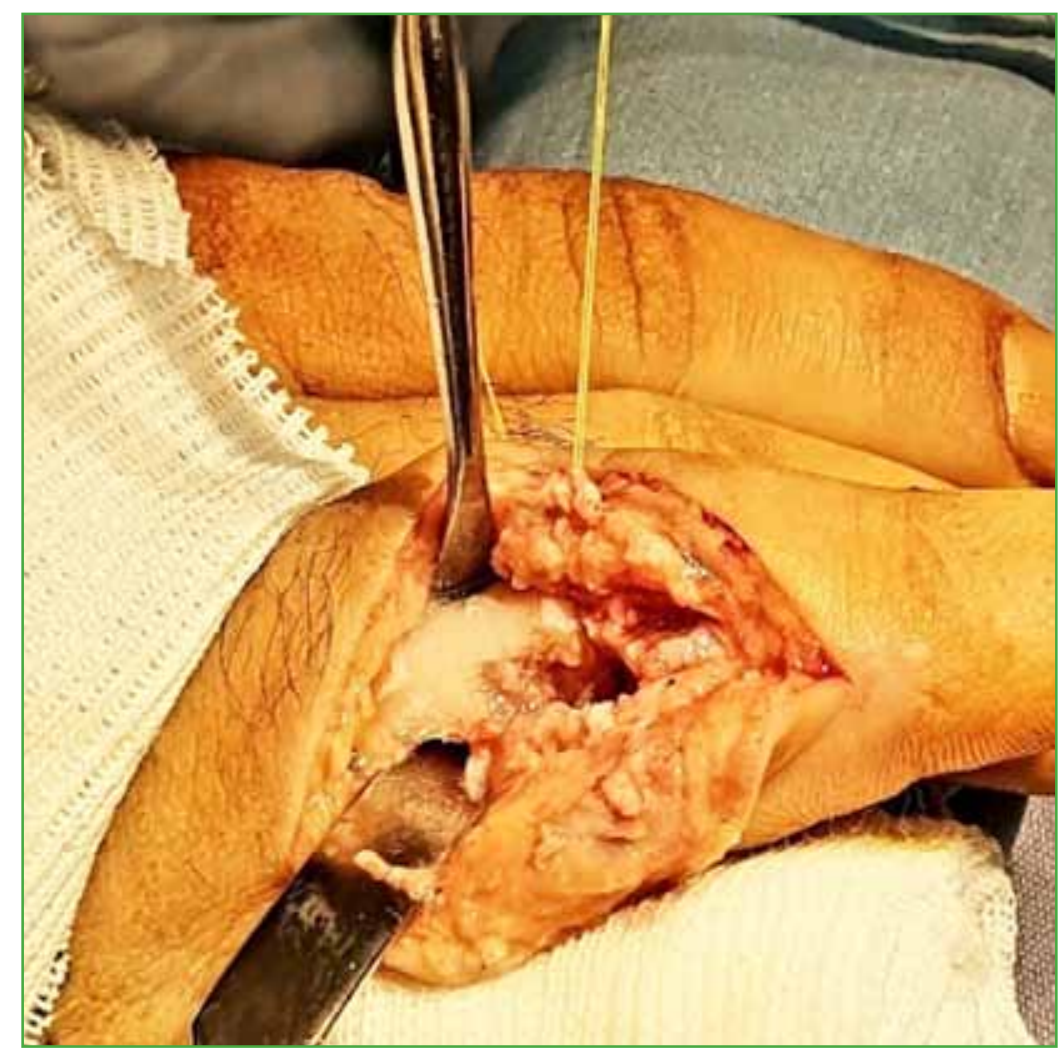

Figura 3. Abordaje y exposición interfalángica proximal.

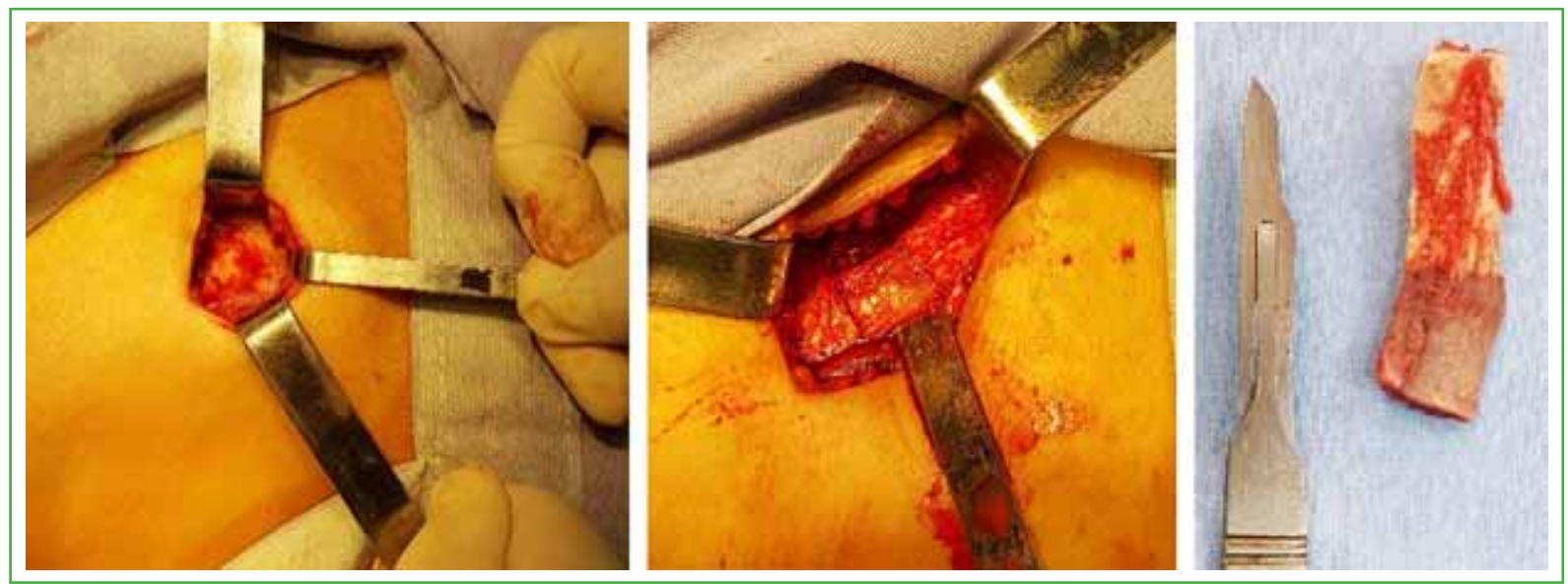

Figura 4. Toma de injerto osteocondral.

\section{Osteosintesis del injerto y montaje del tutor Suzuki}

El injerto fue dividido en dos, de manera longitudinal, para reconstruir la falange media y proximal, ambos con su unión osteocondral. Ambos injertos se fijaron en su porción ósea con dos tornillos de 1,3 mm (Profyle Hand, Stryker®, Mahwah, NJ, EE.UU.) y luego se montó un tutor distractor con técnica de Suzuki, ${ }^{5}$ bajo control con el intensificador de imágenes. Se cerraron las heridas por planos en el dedo anular y el tórax, sin necesidad de drenaje y se colocó una valva antebraquidigital para reposo (Figuras 5 y 6). 


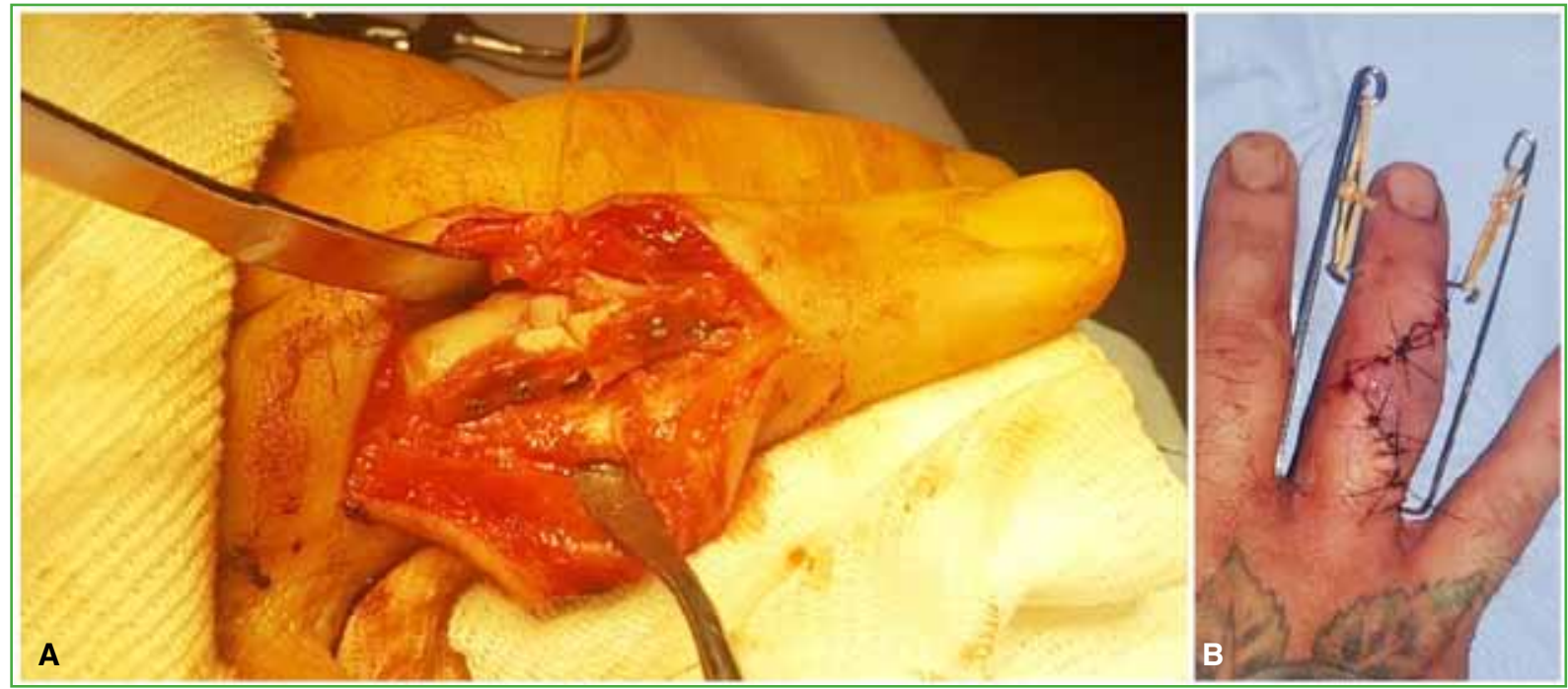

Figura 5. Imágenes intraoperatorias. A. Osteosíntesis con tornillos. B. Distractor colocado.

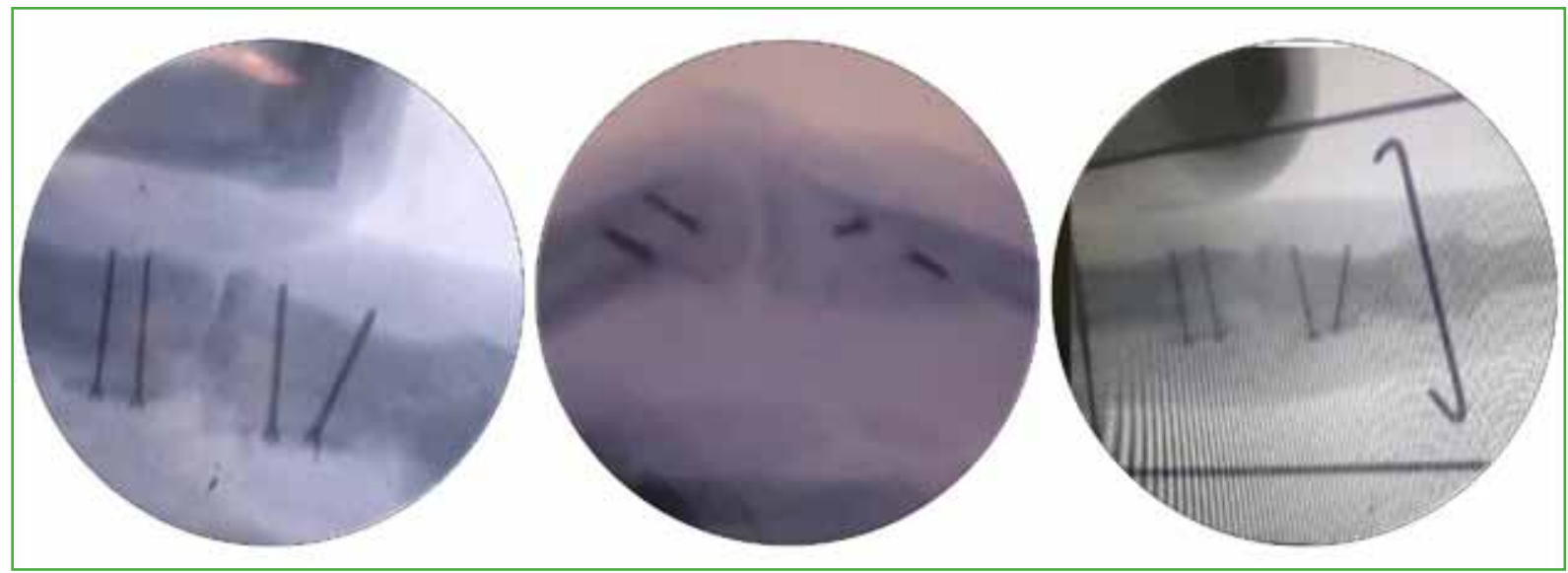

Figura 6. Imágenes radioscópicas intraoperatorias.

\section{Rehabilitación posoperatoria}

Se inició la movilización de la articulación interfalángica proximal del dedo anular a partir del sexto día posoperatorio; en ese momento, se suspendió el uso de la férula de reposo y el paciente comenzó con sesiones de fisiokinesioterapia. El dispositivo de distracción se retiró al mes de la cirugía.

El paciente fue evaluado con controles radiográficos seriados, goniometría del dedo en las consultas y al alta laboral; el dolor se evaluó con la escala analógica visual y el cuestionario DASH. ${ }^{6}$

Al mes de la cirugía, las radiografías revelaron signos claros de consolidación ósea de los dos injertos, con articulación congruente tanto antes de retirar el tutor externo distractor, como después de hacerlo (Figura 7).

A las 10 semanas de la operación, se constató usando goniometría una flexión activa interfalángica proximal de $75^{\circ}$ y una extensión activa de $-15^{\circ}$, con articulación estable.

El paciente se reintegró a sus actividades laborales a los tres meses de la cirugía, sin dolor (escala analógica visual 0) y puntaje DASH ${ }^{6} 14,2$. En las radiografías, se observó la incorporación de los injertos, sin reabsorción y con una articulación congruente (Figura 8). 


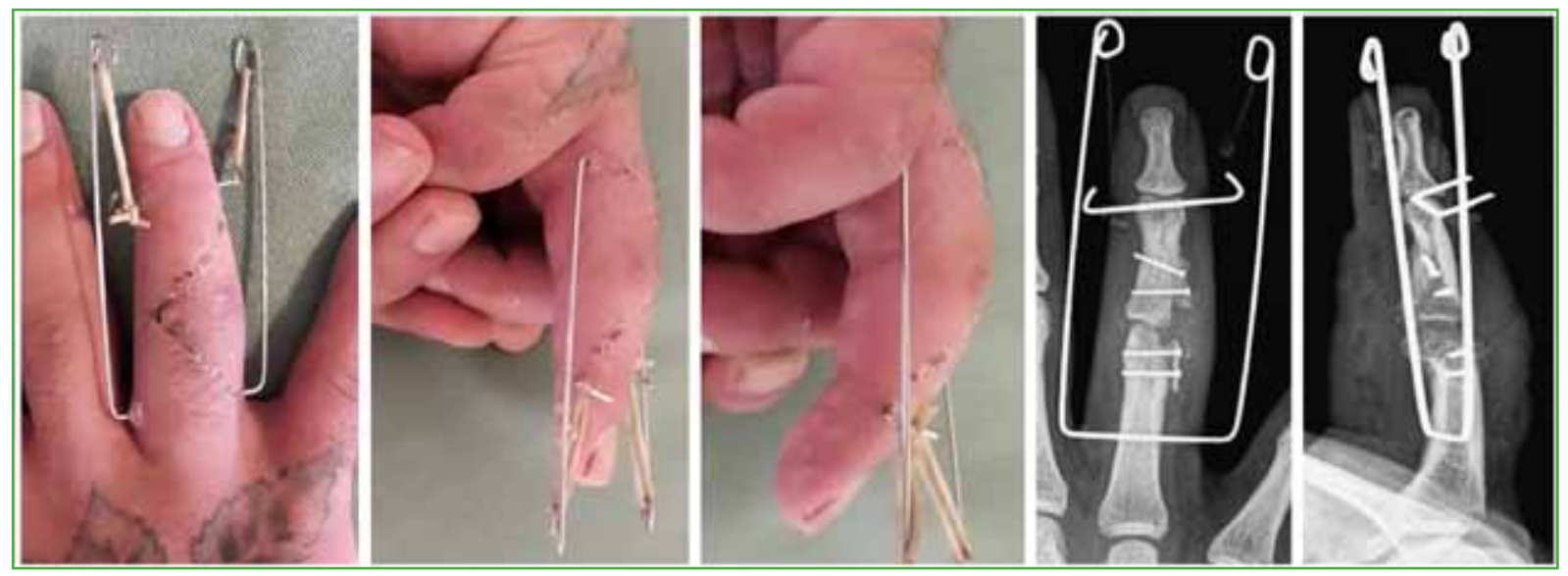

Figura 7. Imágenes clínicas y radiográficas al mes de la cirugía.
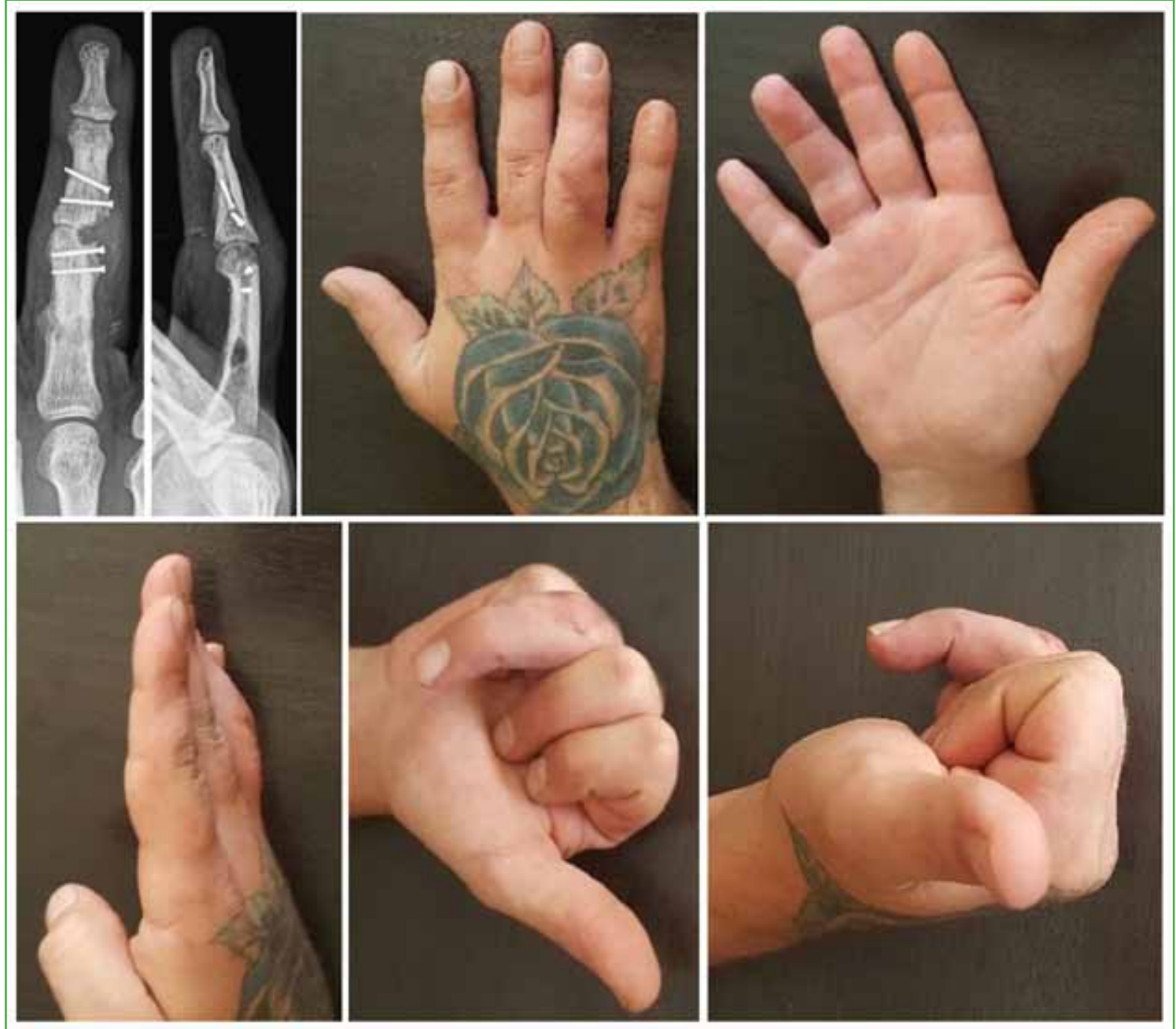

Figura 8. Radiografías y evolución clínica en el momento del alta. 


\section{DISCUSIÓN}

El tratamiento de las fracturas intrarticulares de los dedos suele ser muy complejo, especialmente en aquellos casos que cursan con gran conminución, falta de stock óseo y defecto del cartílago articular. ${ }^{1}$

Se han publicado muchos procedimientos para intentar restaurar la anatomía y la funcionalidad de la articulación interfalángica proximal, como la artroplastia por interposición de Eaton, ${ }^{7}$ la desnervación articular, ${ }^{8}$ el reemplazo articular artificial,,${ }^{910} \mathrm{el}$ trasplante articular parcial no vascularizado del pie $^{11} \mathrm{o}$ de la mano (hueso ganchoso, por ejemplo) ${ }^{12} \mathrm{o}$ el trasplante vascularizado libre de una articulación del dedo del pie para la mano. ${ }^{13,14}$ También, en casos de secuelas, puede realizarse la artrodesis interfalángica proximal con el fin de mejorar la función del dedo afectado, pese a bloquear la movilidad de la articulación en cuestión. ${ }^{15}$

Una alternativa a estas terapéuticas es el injerto osteocondral de costilla que fue descrito inicialmente por Gilles, ${ }^{16}$ en 1920, utilizándolo para reconstruir la articulación temporomandibular. En 1992, Hasegawa y cols. usaron estos injertos en la articulación interfalángica proximal. ${ }^{17}$

La tasa de complicaciones en el sitio dador es baja y permite una reconstrucción del defecto, sin dañar otras articulaciones. Incluso se pueden reemplazar grandes defectos articulares o toda la articulación interfalángica proximal, porque es posible obtener una cantidad considerable de material, sin consecuencias funcionales en el sitio dador. Nuestro paciente no tuvo complicaciones intraoperatorias ni posoperatorias agudas o subagudas.

Reconocemos algunas claras limitaciones en este trabajo. Se trata de un reporte de caso, sin un grupo de control para comparar resultados. Además, el seguimiento posoperatorio poco extendido en el tiempo no nos permite descartar complicaciones a mediano y largo plazo, como necrosis cartilaginosa, reabsorción de injertos o cambios degenerativos articulares.

\section{CONCLUSIÓN}

En el caso clínico presentado, el resultado funcional subjetivo y objetivo fue satisfactorio en el momento del alta laboral. No se pueden descartar dificultades o complicaciones en el futuro.

Conflicto de intereses: Los autores no declaran conflictos de intereses.

ORCID de R. A. Carcuro: https://orcid.org/0000-0002-2292-6774 ORCID de J. A. Bichara: https://orcid.org/0000-0002-3624-2488 ORCID de M. S. Seri: https://orcid.org/0000-0001-7219-712X ORCID de S. J. Faccendini: https://orcid.org/0000-0001-8035-6055 ORCID de I. Camizasca: https://orcid.org/0000-0002-8715-8569
ORCID de E. Massolas: https://orcid.org/0000-0002-6473-667X ORCID de N. Scaiano: https://orcid.org/0000-0002-8869-3504

ORCID de M. E. Romaldini: https://orcid.org/0000-0003-4702-052X

ORCID de J. I. Godoy: https://orcid.org/0000-0002-9628-3740

\section{BIBLIOGRAFÍA}

1. Satake Y, Nanno M, Kodera N, Takai S. Use of a costal osteochondral graft for reconstruction of a proximal phalanx head with a comminuted fracture of the proximal interphalangeal joint. J Nippon Med Sch 2020;87:37-42. https://doi.org/10.1272/jnms.JNMS.2020_87-107

2. Lepage D, Tatu L, Loisel F, Rey PB, Obert L, Parratte B. Anatomical and computed tomography study of the eighth costochondral junction: topography for costochondral graft harvesting. Surg Radiol Anat 2016;38(7):809-15. https://doi.org/10.1007/s00276-016-1635-8

3. Sato K, Nakamura T, Nakamichi N, Okuyama N, Yoshiaki TY, Ikegami H. Finger joint reconstruction with costal osteochondral graft. Tech Hand Up Extrem Surg 2008; 12(3):150-5. https://doi.org/10.1097/BTH.0b013e31816d92ad

4. Loisel F, Pluvy I, Kielwasser H, Panouilleres M, Obert L, Lepage D. Technical note on the harvesting of rib osteochondral autografts for upper limb bone and joint repair surgery. Hand Surg Rehabil 2018;37(6):337-41. https://doi.org/10.1016/j.hansur.2018.07.005

5. Suzuki Y, Matsunaga T, Sato S, Yokoi T. The pins and rubbers traction system for treatment of comminuted intraarticular fractures and fracture-dislocations in the hand. J Hand Surg Br 1994;19(1):98-107. https://doi.org/10.1016/0266-7681(94)90059-0 
6. Hudak PL, Amadio PC, Bombardier C. Development of an upper extremity outcome measure: the DASH (disabilities of the arm, shoulder and hand) [corrected]. The Upper Extremity Collaborative Group (UECG). Am J Ind Med 1996; 29(6):602-8. https://doi.org/10.1002/(SICI)1097-0274(199606)29:6<602:AID-AJIM4>3.0.CO;2-L

7. Malerich MM, Eaton RG. The volar plate reconstruction for fracture-dislocation of the proximal interphalangeal joint. Hand Clin 1994;10(2):251-60. PMID: 8040203

8. Jiménez I, Marcos-García A, Muratore G, Caballero-Martel J, Medina J. Denervation for proximal interphalangeal joint osteoarthritis. J Hand Surg Am 2020;45(4):358.e1-358.e5. https://doi.org/10.1016/j.jhsa.2019.07.012

9. Wagner ER, Luo TD, Houdek MT, Kor DJ, Moran SL, Rizzo M. Revision proximal interphalangeal arthroplasty: an outcome analysis of 75 consecutive cases. J Hand Surg Am 2015;40:1949-55. https://doi.org/10.1016/j.jhsa.2015.05.015

10. Wagner ER, Weston JT, Houdek MT, Luo TD, Moran SL, Rizzo M. Medium-term outcomes with pyrocarbon proximal interphalangeal arthroplasty: a study of 170 consecutive arthroplasties. J Hand Surg Am 2018;43(9):797805. https://doi.org/10.1016/j.jhsa.2018.06.020

11. Podolsky D, Mainprize J, McMillan C, Binhammer P. Comparison of third toe joint cartilage thickness to that of the finger proximal interphalangeal (PIP) joint to determine suitability for transplantation in PIP joint reconstruction. $J$ Hand Surg Am 2011;36(12):1950-8. https://doi.org/10.1016/j.jhsa.2011.09.013

12. Leclère FM, Haug L, Meier R, Surke C, Unglaub F, Vögelin E. Non-vascularized partial joint transfer for finger proximal interphalangeal joint reconstruction: a series of 9 patients. Arch Orthop Trauma Surg 2020;140(1):139-44. https://doi.org/10.1007/s00402-019-03301-9

13. Foucher G, Merle M, Maneaud M, Michon J. Microsurgical free partial toe transfer in hand reconstruction: a report of 12 cases. Plast Reconstr Surg 1980;5:616-27. https://doi.org/10.1097/00006534-198005000-00013

14. Dautel G. Vascularized toe joint transfers to the hand for PIP or MCP reconstruction. Hand Surg Rehabil 2018;37(6):329-36. https://doi.org/10.1016/j.hansur.2018.03.008

15. Millrose M, Zach A, Kim S, Güthoff C, Eisenschenk A, Vonderlind HC. Biomechanical comparison of the proximal interphalangeal joint arthrodesis using a compression wire. Arch Orthop Trauma Surg 2019;139(4):577-81. https://doi.org/10.1007/s00402-019-03119-5

16. Gillies HD. Plastic surgery of the face. London: Oxford University Press; 1920:13-15, 177-182.

17. Hasegawa T, Yamano Y. Arthroplasty of the proximal interphalangeal joint using cartilage grafts. $J$ Hand Surg Br 1992;17:583-5. https://doi.org/10.1016/s0266-7681(05)80248-7 